\title{
Personal-Organizational Value Congruence as a Mediator Between Personality and Employee Attitudes
}

\author{
Doruk Uysal-Irak
}

Additional information is available at the end of the chapter

http://dx.doi.org/10.5772/intechopen.68239

\begin{abstract}
The purpose of this chapter was to examine the role of personal-organizational value congruence as a mediator between personality (neuroticism and extraversion) and employee attitudes (job satisfaction, life satisfaction and turnover intentions). Three hundred and twenty employees participated in the study (171 female and 149 male). A model generated in this study was tested using SEM in AMOS 21.0. Results showed that neuroticism and extraversion were related to personal-organizational value congruence. Moreover, value congruence was a full mediator between personality dimensions and employee attitudes (job satisfaction, life satisfaction and turnover intentions). Only partial mediation was found between neuroticism and life satisfaction. The results underlined two important factors: (1) influence of personality on perceptions of value congruence and (2) value congruence acts like a mediator between personality and employee attitudes.
\end{abstract}

Keywords: value congruence, personality, job satisfaction, life satisfaction, turnover intentions, person-organization fit

\section{Introduction}

Personality has been evaluated as an important predictor of various employee attitudes [1]. For example, job satisfaction was found as significantly related to both neuroticism and extraversion [2]. Also, those two traits were found as they are the strongest predictors of life satisfaction (see in Ref. [3]). In addition, positive affectivity [4] and neuroticism [5] can also predict turnover intentions. Therefore, personality is an important predictor for employees' well-being and satisfaction at the workplace. This relationship has been described in many fields; however, there is lack of research examining the processes which explain the relationship between personality and employee attitudes. According to one idea, personality could 
affect peoples' reactions to specific environments as they can shape values and preferences [6] and this would change individual's perceptions about the congruence between themselves and their environment. From this point of view, it can be concluded that the congruence between personality and work environment would be an important variable (see in Refs. [7-10]. Despite the importance of personality on employee attitudes and its influence on organizational outcomes, there is relatively little research regarding how different personalities could influence perceptions of value congruence between employees and their organizations. Of the published research, most studies focus on either the relation between different personalities and how various traits are attracted to certain environments $[6-8,11,12]$ or other dimensions such as vocational interests on fit perceptions [13]. However, in order to explore the processes between personality and employee attitudes, studies should examine the role of value congruence at workplace.

This study aims to explore the relationship between personality (neuroticism and extraversion) and employee attitudes (job satisfaction, life satisfaction and turnover intentions). It has been hypothesized that people who are extraverted would have perceptions of high personalorganizational value congruence which would increase their life satisfaction and job satisfaction, whereas decrease their turnover intentions. On the other hand, people who are high in neuroticism would have perceptions of low personal-organizational value congruence, which in turn decrease their job satisfaction, life satisfaction and increase their turnover intentions.

\subsection{Describing personal-organizational value congruence}

One of the perspectives in person-environment fit literature is called supplementary fit $[9,14]$. According to this perspective, people may believe they fit the environment because they share similar characteristics, values, norms or interests with the others in their environment. This kind of fit was also named as value congruence [15] because it underlines the similarity between the values of individuals and organizational values $[9,16]$. This is the most commonly used operational definition of fit [9]. People need to locate themselves within society and they use group membership to do this according to Social Identity Theory [17]. Being a member of a social group shapes individual's self-concept [17]. Similar attributes between organizational identity and individual self-concept create organizational identification [18]. However, when there is no congruency between personal and organizational attributes, cognitive conflict occurs and negative attitudes appear [15].

In other words, personal-organizational value congruence has significant relation with several attitudes. Theoretically, when there is a similarity between the values of an individual and the environment, they will be more likely to have higher job satisfaction and be less likely to leave their job [19-22] because their attitudes should be more positive [15]. Moreover, the congruence between an employee and the organization has an influence on organizational performance [23] and organizational citizenship behaviour [24]. On the other side, value incongruence will lead to cognitive dissonance and dissatisfaction [25]. Therefore, personalorganizational value congruence is an important predictor for several employee attitudes.

Hypothesis 1: Personal-organizational value congruence will be positively related to job satisfaction, life satisfaction and will be negatively related to turnover intentions. 


\subsection{Role of personality on personal-organizational value congruence}

Person-environment fit studies have been grounded in the interactionist theory of behaviour, which considers the effects of personality in combination with situational factors on important outcomes [14]. As it was stated [6], personality could affect individuals' reactions to specific environments as they can shape preferences. In order to understand and gain more comprehensive knowledge about fit-in other words, congruence-we need more research studying the role of personality differences in person-environment congruence [6, 26]. Most studies about personality and congruence focused on how different personalities were attracted to certain environments [6]. For example, researchers (see in Ref. [6]) found that although people high in neuroticism prefer to work in innovative organizational cultures, people high in conscientiousness prefer to work in both innovative and outcome-oriented organizational cultures. In one study examining the impact of personality on job performance, researchers have shown that personality traits are related to performance when there is a match with the work environments [27]. For example, extraversion is related to performance when the workplace is competitive, whereas agreeableness is related to performance when cooperation is expected in the workplace [27]. Moreover, a poor fit between personality and the characteristics of the workplace could result in high turnover [28].

There are no direct studies about how personality can change individual perceptions about the congruence between themselves and their organization. However, the studies showed that people focus only on one set of attributes in their environment, consistent with their affective experiences [29], their judgments of the same event may also be different depending on their personality [30-32]. Therefore, personality might change what individuals focus on their environment. Extraversion and neuroticism are two of the Big Five dimensions [33]. Extraverted people more likely focus on positive information but neurotic people more often focus on negative information [34], which underlines how personality influences individual perceptions about their environment. Cognition bias has an impact on employees' evaluations about their work environments or their jobs (see in [35]). Various approaches provide support for this claim regarding the influence of personality on evaluations of environments such as Stimulus-Organism Response theory [36] or Affective Events theory [37]. Therefore, people may have different perceptions about their personal and organizational value congruence as a consequence of extraversion and neuroticism.

Hypothesis 2: Neuroticism and extraversion will be related to personal-organizational value congruence.

\subsection{Personal-organizational value congruence as a mediator between personality and employee attitudes}

Person-environment fit literature frequently studied antecedents and consequences of the congruence between employee and their environments. However, perceptions of the congruence can also be a mediator between variables, which was rarely mentioned in the field. Some researchers underlined that the role of personality in the development of a sense of personenvironment congruence and the interplay of personality and congruence on outcomes, such as commitment and satisfaction fit, is still in the infancy stages of research [38]. If personality 
has an impact on how employees evaluate their environments or if it differentiates what kind of information employees prefer to focus, then it will first determine perceptions of personalorganizational value congruence and then this will alter employee attitudes.

Hypothesis 3: Personal-organizational value congruence will be a mediator between personality (extraversion and neuroticism) and attitudes (job satisfaction, life satisfaction and turnover intentions).

\subsection{Current research}

Overall, the aim of the research was to test the model including three main hypotheses. It is important to explore how influential personality can be on perceptions about person-environment congruence. Moreover, it is also important to explore mediation effect of personalorganizational value congruence among personality and employee attitudes. A model was generated in order to test the hypotheses (see Figure 1).

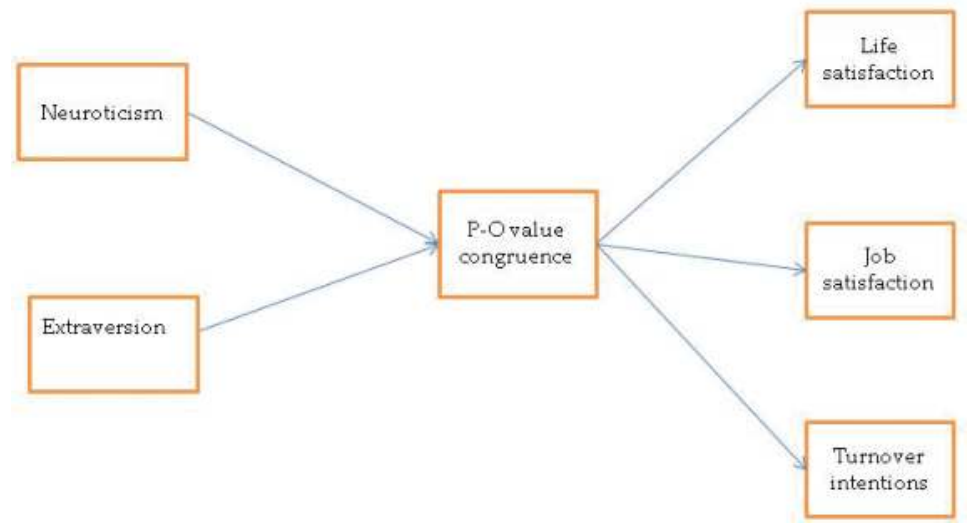

Figure 1. Model tested.

\section{Method}

\subsection{Participants}

In total, 320 employed people were recruited through snowball sampling who were working in a full-time job. Participants completed a 15-minute paper-pencil survey about personalorganizational value congruence and personal outcomes related to work. Of these, 171 were female and 149 were male, with a mean age of $32(\mathrm{SD}=8.78)$. Fifty-three per cent of the participants were single and $48 \%$ were married. Most of the employees (88\%) were working in private companies. Mean tenure of the participants was $5.5(\mathrm{SD}=5.4)$. 


\subsection{Measures}

Neuroticism and extraversion: In order to measure the neuroticism and extraversion traits, Eysenck Personality Questionnaire Scale [39] with Cronbach's Alpha of 0.81 for extraversion and 0.72 for neuroticism was used in this study. The scale was developed by Francis, Brown and Philipchalk. Both extraversion (e.g. item, Are you a talkative person?) and neuroticism (e.g. item, Do you often feel lonely?) subscales consisted of six items.

Value congruence: In order to measure personal and organizational value congruence, fiveitem scale [40] was used. The scale developed by Resick, Baltes and Shantz includes items such as 'The values of this organization are similar to my own values'. The Cronbach's Alpha reliability of this scale was 0.89 .

Life satisfaction: Also, life satisfaction was measured by Satisfaction with Life Scale [41] with five-item scale by Diener, Emmons, Larsen and Griffin. The scale aims to assess global life satisfaction with a reliability of 0.86 (e.g. item; I am satisfied with my life).

Job satisfaction was measured with five-item scale, named Overall Job Satisfaction Scale, developed by Brayfield and Rothe [42] and designed to assess how participants feel about their jobs (e.g. item, I am enthusiastic about my work). It has Cronbach's Alpha of 0.81.

Turnover intentions were measured by three-item scale of Cammann, Fichman, Jenkins and Klesh [43] with a reliability of 0.78 . At last, participants were also asked to indicate their gender, age, organizational tenure, type of industry and type of employment.

\section{Results}

Means, standard deviations, reliabilities and zero-order correlations for the measured variables are shown in Table 1. All variables were significantly correlated to each other except extraversion and turnover intentions. Highest correlations were between job satisfaction and turnover intentions $(\mathrm{r}=-0.61, \mathrm{p}<0.001)$, value congruence and turnover intentions $(\mathrm{r}=-0.54, \mathrm{p}<0.001)$ and value congruence and job satisfaction $(r=0.54, p<0.001)$. An initial analysis yielded no significant influence of gender on outcome variables (i.e. personal-organizational value congruence, neuroticism, extraversion, life satisfaction, job satisfaction and turnover intentions).

In order to test the hypothesis, the measurement model (Figure 1) was examined whether it has an acceptable fit to the data. The hypothesized model was tested using the maximum likelihood method in AMOS 21.0. The initial test of the measurement model resulted in a good fit to the data except the value of RMSEA $\left(\chi^{2}=34.59, \chi^{2} / \mathrm{df}=4.9, \mathrm{p}=0.00, \mathrm{GFI}=0.97, \mathrm{CFI}=0.93\right.$ and $\left.\mathrm{RMSEA}=0.11\right)$. On the basis of the modification indices model, one direct path from neuroticism to life satisfaction was included. This revised model had a better fit to the data $\left(\chi^{2}=12.79, \chi^{2} / \mathrm{df}=2.1, \mathrm{p}=0.05, \mathrm{GFI}=\right.$ $0.99, \mathrm{CFI}=0.98$ and RMSEA $=0.06)$, as evidenced by a significant Chi-square difference test $\left(\Delta \chi^{2}=\right.$ $21.8, \mathrm{p}<0.001)$. According to that, personal-organizational value congruence is a mediator between personality and employee attitudes (life satisfaction and job satisfaction). Partial mediation was found between neuroticism and life satisfaction (see Figure 2). 


\begin{tabular}{|c|c|c|c|c|c|c|c|c|}
\hline & $\mathbf{M}$ & SD & 1 & 2 & 3 & 4 & 5 & 6 \\
\hline 1. Neuroticism & 2.34 & 1.85 & $(0.72)$ & & & & & \\
\hline 2. Extraversion & 4.39 & 1.86 & $-0.26^{* * *}$ & $(0.81)$ & & & - & \\
\hline $\begin{array}{l}\text { 3. Personal- } \\
\text { organizational } \\
\text { congruence }\end{array}$ & 17.03 & 4.09 & $-0.19^{* * *}$ & $0.17^{* *}$ & $(0.89)$ & & & \\
\hline 4. Job satisfaction & 18.34 & 3.77 & $-0.25^{* * *}$ & $0.18^{* * *}$ & $0.54^{* * *}$ & $(0.81)$ & & \\
\hline 5. Life satisfaction & 16.49 & 4.39 & $-0.34^{* * * *}$ & $0.17^{* *}$ & $0.35^{* * *}$ & $0.42^{* * *}$ & $(0.86)$ & \\
\hline $\begin{array}{l}\text { 6. Turnover } \\
\text { intentions }\end{array}$ & 7.33 & 2.59 & $0.18^{* * *}$ & -0.09 & $-0.54^{* * *}$ & $-0.61^{* * *}$ & $-0.27^{* * *}$ & $(0.78)$ \\
\hline
\end{tabular}

Note: $\mathrm{N}=320$.

${ }^{* *} \mathrm{p}<0.01$

$* * * \mathrm{p}<0.001$.

Table 1. Means, standard deviations, reliabilities and inter-scale correlations for measured research variables.

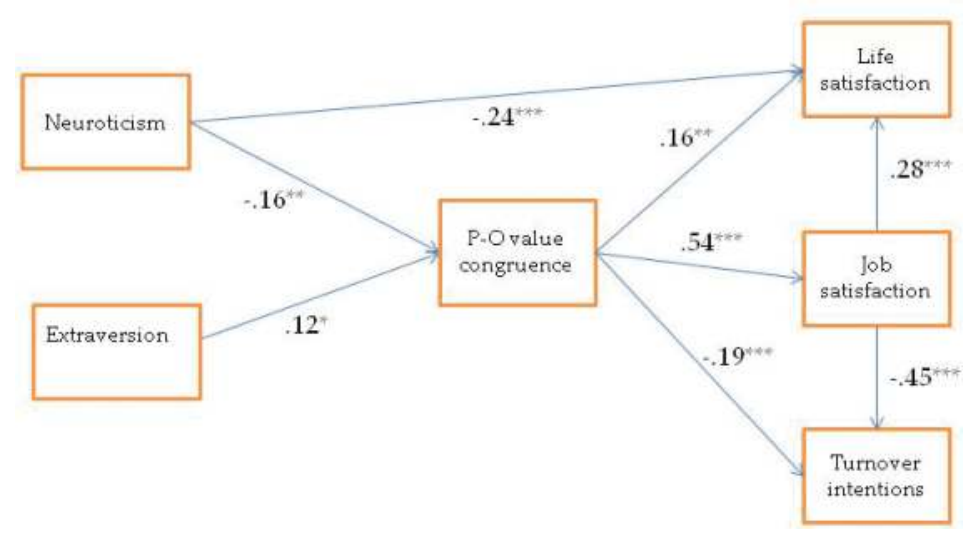

Figure 2. Revised model. Standardized regression weights were given. ${ }^{*} \mathrm{p}<0.05,{ }^{* *} \mathrm{p}<0.01,{ }^{* * *} \mathrm{p}<0.001$.

\section{Discussion}

It is believed that personality has an influence on how people perceive, explain, recognize or focus on their environment and how they react to their environment. If personality shapes perceptions of personal-organizational value congruence, some traits may predispose individuals to always perceive their congruence as good with their environment, whereas others would always perceive their congruence as poor with their environment, regardless of their actual congruence.

In conclusion, the results of the study confirmed the literature that people with higher extraversion tend to have consistently more positive reports of work-related attitudes, even in the 
same objective conditions, compared to people with lower extraversion (see in [44-47]). In addition, we can conclude that people who are negative in general were the ones who are less satisfied with their job. Moreover, this result confirmed that perception of personal-organizational value congruence is a mediator between personality and attitudes. The study revealed that personality can change one's perception about value congruence which in turn can influence their job-related attitudes.

Exploring the relation between the personal-organizational value congruence and personality will not only introduce new perspectives to the ways of assessing employee behaviours but it will also be useful for organizational practices, such as selection or recruitment, since the notion of fit is important for those practices [48-50]. If personality has an impact on employees' perceptions about personal-organizational value congruence, the association between congruence and individual outcomes, such as satisfaction or stress, will need to be reassessed, and organizational practices and interventions may need to be revised to take into account the role of personality in the workplace.

The current study also has some important limitations. First, it was based on a cross-sectional design which makes it hard to make causal inferences. There is a strong need for more longitudinal research in this area which examines any changes on personal-organizational value congruence. A second limitation is that the study used a self-report measure which raises the issue of common method variance that may have inflated the correlations. However, other methods such as observer ratings may equally be affected by some bias [51]. More research is needed in order to validate findings of this study and to examine the role of personality on perceptions about personal-organizational value congruence.

\section{Author details}

Doruk Uysal-Irak

Address all correspondence to: doruk.uysalirak@eas.bau.edu.tr

Department of Psychology, Bahçesehir University, Turkey

\section{References}

[1] Saari LM, Judge TA. Employee attitudes and job satisfaction. Human Resources Management. 2004;43(4):395-407

[2] Judge TA, Heller D, Mount M. Five-factor model of personality and job satisfaction: A meta-analysis. Journal of Applied Psychology. 2002;87(3):530-541

[3] Schimmack U, Oishi S, Furr RM, Funder DC. Personality and life satisfaction: A facet level analysis. Personality and Social Psychology Bulletin. 2004;30(8):1062-1075 
[4] Chiu RK, Francesco AM. Dispositional traits and turnover intention: Examining the mediating role of job satisfaction and affective commitment. International Journal of Manpower. 2003;24(3):284-298

[5] Zimmerman RD. Understanding the impact of personality traits on individuals' turnover decisions: A meta-analytic path model. Personnel Psychology. 2008;61:309-348

[6] Judge TA, Cable DM. Applicant personality, organizational culture and organizational culture. Personnel Psychology. 1997;50:359-394

[7] Burke RJ, Deszca E. Preferred organizational climates of Type A individuals. Journal of Vocational Behavior. 1982;21:50-59

[8] Cable DM, Judge TA. Pay preferences and job search decisions: A person organization fit perspective. Personnel Psychology. 1994;47:317-348

[9] Kristof AL. Person-organization fit: An integrative review of its conceptualizations, measurement and implications. Personnel Psychology. 1996;49:1-49

[10] Spokane AR. A review of research on person-environment congruence in Holland's theory of careers. Journal of Vocational Behavior. 1985;26:306-343

[11] Holland JL. Making Vocational Choices. Englewood Cliffs, NJ: Prentice Hall; 1985

[12] O'Reilly CA. Personality-job fit: Implications for individual attitudes and performance. Organizational Behavior and Human Performance. 1977;18:36-46

[13] Ehrhart KH, Makransky G. Testing vocational interests and personality as predictors of person-vocation and person-job fit. Journal of Career Assessment. 2007;15(2):206-226

[14] Muchinsky PM, Monahan CJ. What is person-environment congruence? Supplementary versus complementary models of fit. Journal of Vocational Behavior. 1987;31:268-277

[15] Cable DM, Edwards JR. Complementary and supplementary fit: A theoretical and empirical integration. Journal of Applied Psychology. 2004;89(5):822-834

[16] Chatman CA. Matching people and organizations: Selection and socialization in public accounting firms. Administrative Science Quarterly. 1991;36:459-484

[17] Tajfel H, Turner JC. The social identity theory of intergroup behavior. In: Worchel S, Austin SG, editors. Psychology of Intergroup Relations. $2^{\text {nd }}$ ed. Chicago, IL: Nelson Hall; 1986

[18] Dutton JE, Dukerich JM, Harquail CV. Organizational images and member identification. Administrative Science Quarterly. 1994;39:239-263

[19] Lee TW, Mitchell TR. An alternative approach: The unfolding model of voluntary employee turnover. Academy of Management Review. 1994;19(1):51-89

[20] Lee TW, Mowday RT. Voluntarily leaving an organization: An empirical investigation of Steers and Mowday's model of turnover. Academy of Management Journal. 1987;30(30):721-743 
[21] Schneider B. The people make the place. Personnel Psychology. 1987;40:437-453

[22] Steers RW, Mowday RT. Employee turnover and post-decision accommodation processes. In: Cummings LL, Staw BM, editors. Research in Organizational Behavior. Greenwich, CT: JAI Press; 1981

[23] Arthur Jr. W, Bell S, Villado AJ, Doverspike D. The use of person-organization fit in employment decision making: An assessment of its criterion related validity. Journal of Applied Psychology. 2006;91(4):786-801

[24] Cable DM, DeRue DS. The convergent and discriminant validity of subjective fit perceptions. Journal of Applied Psychology. 2002;87(5):875-884

[25] O'Reilly CA, Chatman J, Caldwell DF. People and organizational culture: A profile comparison approach to assessing person-organization fit. Academy of Management Journal. 1991;34(3):487-516

[26] Judge TA. The future of person-organization fit research: Comments, observations and a few suggestions. In: Ostroff C, Judge TA, editors. Perspectives on Organizational Fit. New York: Lawrence Erlbaum; 2007. pp. 417-447

[27] Barrick MR, Mitchell TR, Stewart GL. Situational and motivational influences on trait-behavior relationships. In: Barrick MR, Ryan AM, editors. Personality and Work: Reconsidering the Role of Personality in Organizations. San Francisco: Jossey-Bass; 2003. pp. 60-82

[28] Ryan AM, Kristof-Brown AL. Focusing on personality in person-organization fit research: Unaddressed issue. In: Barrick MR, Ryan AM, editors. Personality and Work: Reconsidering the Role of Personality in Organizations. San Francisco: Jossey-Bass; 2003. pp. 262-288

[29] Staw BM. Organizational behavior: A review and reformulation of the field's outcome variables. Annual Review of Psychology. 2004;35:627-666

[30] Ogunfowara B. The impact of ethical leadership within the recruitment context: The roles of organizational reputation, applicant personality, and value congruence. The Leadership Quarterly. 2014;25(3):528-543

[31] Schuh SC, Quaquebeke NV, Keck N, Göritz AS, Cremer DD, Xin KR. Does it take more than ideals? How counter-ideal value congruence shapes employees' trust in the organization. Journal of Business Ethics. 2016;1-17

[32] Gardner WL, Reithel BJ, Cogliser CC, Walumbwa FO, Foley RT. Matching personality and organizational culture. Management Communication Quarterly. 2012;26(4):585-622

[33] McCrae RR, Costa PT Jr. Validation of the five-factor model of personality across instruments and observers. Journal of Personality and Social Psychology. 1987;52:81-90

[34] Noguchi K, Gohm CL, Dalsky DJ. Cognitive tendencies of focusing on positive and negative information. Journal of Research in Personality. 2006;40:891-910 
[35] Levin I, Stokes JP. Dispositional approach to job satisfaction: Role of negative affectivity. Journal of Applied Psychology. 1989;74:752-758

[36] Judge TA, Larsen RJ. Dispositional affect and job satisfaction: A review and theoretical extension. Organizational Behavior and Human Decision Processes. 2001;86(1):67-98

[37] Weiss HM, Cropanzano R. Affective events theory: A theoretical discussion of the structure, causes, and consequences of affective experience at work. In: Staw BM, Cummings LL, editors. Research in Organizational Behavior: An Annual Series of Analytical Essays and Critical Reviews. US: Elsevier Science; 1996. pp. 1-74

[38] Greguras GJ, Diefendorff JM. Different fit satisfy different needs: Linking person-environment fit to employee commitment and performance using self-determination theory. Journal of Applied Psychology. 2009;94:465-477

[39] Francis LJ, Brown LB, Philipchalk R. The development of an abbreviated form of the Revised Eysenk Personality Questionnaire (EPQR-A): Its use among students in England, Canada, the USA and Australia. Personality and Individual Differences. 1992;13:443-449

[40] Resick CJ, Baltes BB, Shantz CW. Person-organization fit and work related attitudes and decisions: Examining interactive effects with job fit and conscientiousness. Journal of Applied Psychology. 2007;92(5):1446-1455

[41] Diener E, Emmons RA, Larsen RJ, Griffin S. The satisfaction with life scale. Journal of Personality Assessment. 1985;49(1):71-75

[42] Brayfield AH, Rothe HF. An index of job satisfaction. Journal of Applied Psychology. 1951;35:307-311

[43] Cammann C, Fichman M, Jenkins D, Klesh J. The Michigan Organizational Assessment Questionnaire. Unpublished Manuscript. University of Michigan, Ann Arbor Michigan; 1979

[44] Cropanzano R, James K, Konovsky MA. Dispositional affectivity as a predictor of work attitudes and job performance. Journal of Organizational Behavior. 1993;14(6):595-606

[45] George JM. Mood and absence. Journal of Applied Psychology. 1989;74:317-324

[46] George JM. State or trait: Effects of positive mood on prosocial behaviors at work. Journal of Applied Psychology. 1991;76:299-307

[47] Thoresen CJ, Kaplan SE, Barsky AP, Warren CR, Chermont K. The affective underpinnings of job perceptions and attitudes: A met-analytic review and integration. Psychological Bulletin. 2003;129(6):914-945

[48] Cable DM, Yu KYT. How selection and recruitment practices develop the beliefs used to assess fit. In: Ostroff C, Judge TA, editors. Perspectives on Organizational Fit. New York: Lawrence Erlbaum; 2007. pp. 155-182

[49] Lauver KJ, Kristof-Brown A. Distinguishing between employees' perceptions of personjob and person-organization fit. Journal of Vocational Behavior. 2001;59:454-470 
[50] Saks AM, Ashforth BE. A longitudinal investigation of the relationships between job information sources, applicant perceptions of fit, and work outcomes. Personnel Psychology. 1997;50:395-426

[51] Spector PE. Method variance in organizational research: Truth or urban legend?. Organizational Research Methods. 2006;9:221-232 
